\title{
Erratum to "Unexpected High Response Rate to Traditional Therapy after Dendritic Cell-Based Vaccine in Advanced Melanoma: Update of Clinical Outcome and Subgroup Analysis”
}

\author{
Laura Ridolfi, ${ }^{1}$ Massimiliano Petrini, ${ }^{1}$ Laura Fiammenghi, ${ }^{1}$ Anna Maria Granato, ${ }^{1}$ \\ Valentina Ancarani, ${ }^{1}$ Elena Pancisi, ${ }^{1}$ Emanuela Scarpi, ${ }^{2}$ Massimo Guidoboni, ${ }^{1}$ \\ Giuseppe Migliori, ${ }^{3}$ Stefano Sanna, ${ }^{4}$ Francesca Tauceri, ${ }^{5}$ Giorgio Maria Verdecchia, ${ }^{5}$ \\ Angela Riccobon, ${ }^{1}$ Linda Valmorri, ${ }^{2}$ and Ruggero Ridolfi ${ }^{1}$ \\ ${ }^{1}$ Immunotherapy Unit, Department of Medical Oncology, Scientifc Institute of Romagna for the Study \\ and Treatment of Cancer (I.R.S.T.), 47014 Meldola, Italy \\ ${ }^{2}$ Unit of Biostatistics and Clinical Trials, Scientifc Institute of Romagna for the Study and Treatment of Cancer (I.R.S.T.), \\ 47014 Meldola, Italy \\ ${ }^{3}$ Blood Transfusion Unit, Morgagni-Pierantoni Hospital, 47014 Forlì, Italy \\ ${ }^{4}$ Thoracic Surgery Unit, Morgagni-Pierantoni Hospital, 47014 Forli, Italy \\ ${ }^{5}$ Advanced Oncological Surgery Unit, Morgagni-Pierantoni Hospital, 47014 Forli, Italy
}

Correspondence should be addressed to Laura Ridolfi, g.tierney@irst.emr.it

Received 27 December 2010; Accepted 7 February 2011

Copyright (c) 2011 Laura Ridolfi et al. This is an open access article distributed under the Creative Commons Attribution License, which permits unrestricted use, distribution, and reproduction in any medium, provided the original work is properly cited.

The authors would like to add Dr. Linda Valmorri to the authors' list. Thus, the authors' list will be: Laura Ridolfi, Massimiliano Petrini, Laura Fiammenghi, AnnaMaria Granato, Valentina Ancarani, Elena Pancisi, Emanuela Scarpi, Massimo Guidoboni, Giuseppe Migliori, Stefano Sanna, Francesca Tauceri, Giorgio Maria Verdecchia, Angela Riccobon, Linda Valmorri, and Ruggero Ridolfi. 


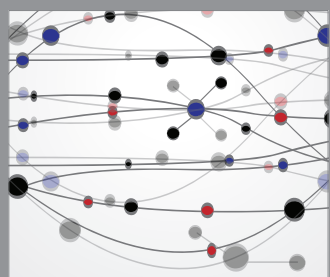

The Scientific World Journal
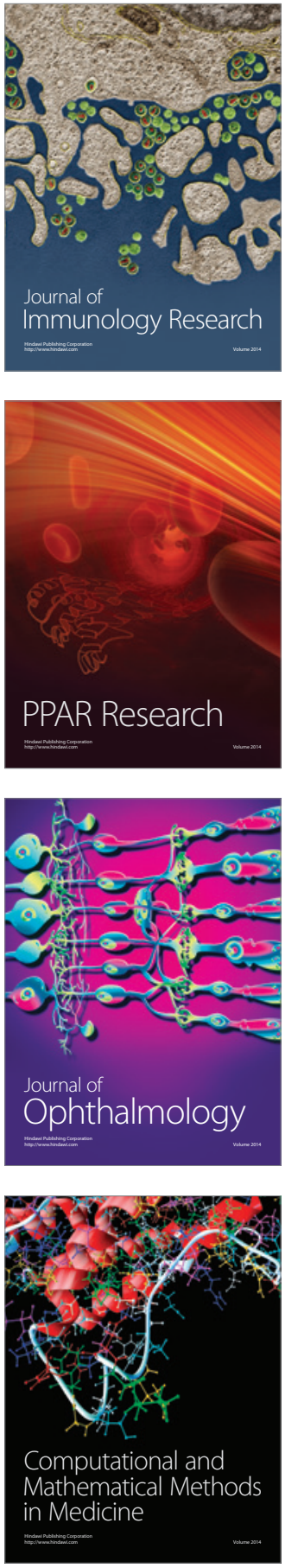

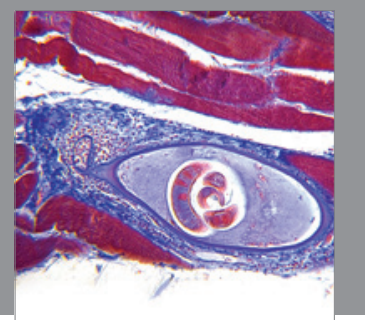

Gastroenterology

Research and Practice
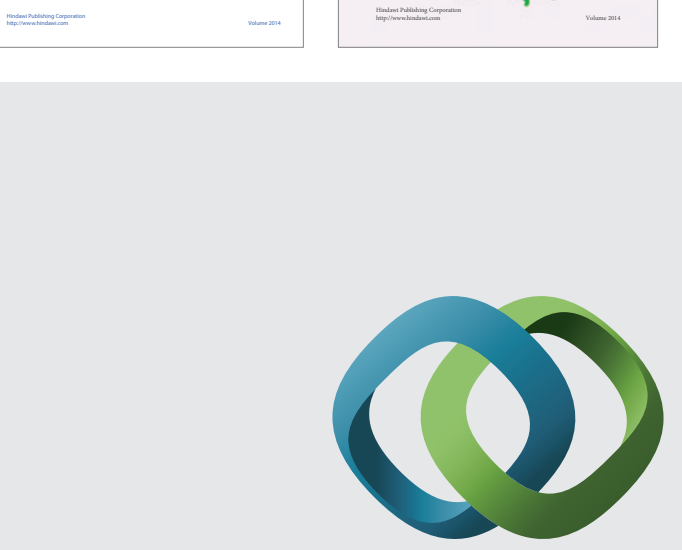

\section{Hindawi}

Submit your manuscripts at

http://www.hindawi.com
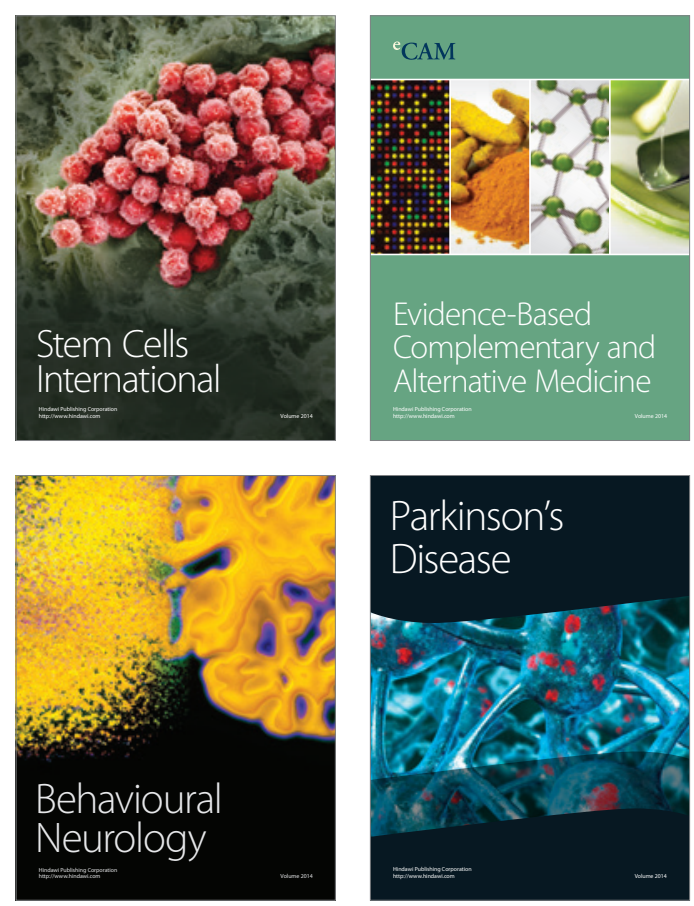

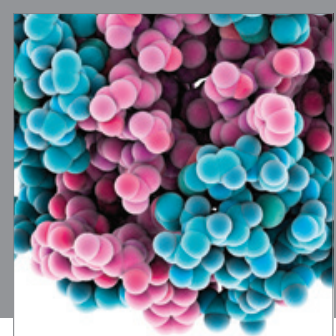

Journal of
Diabetes Research

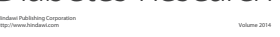

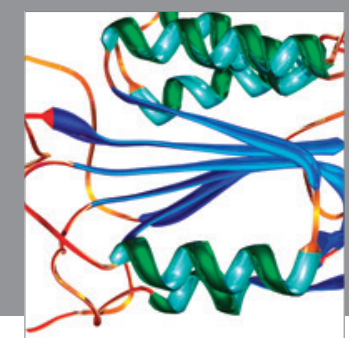

Disease Markers
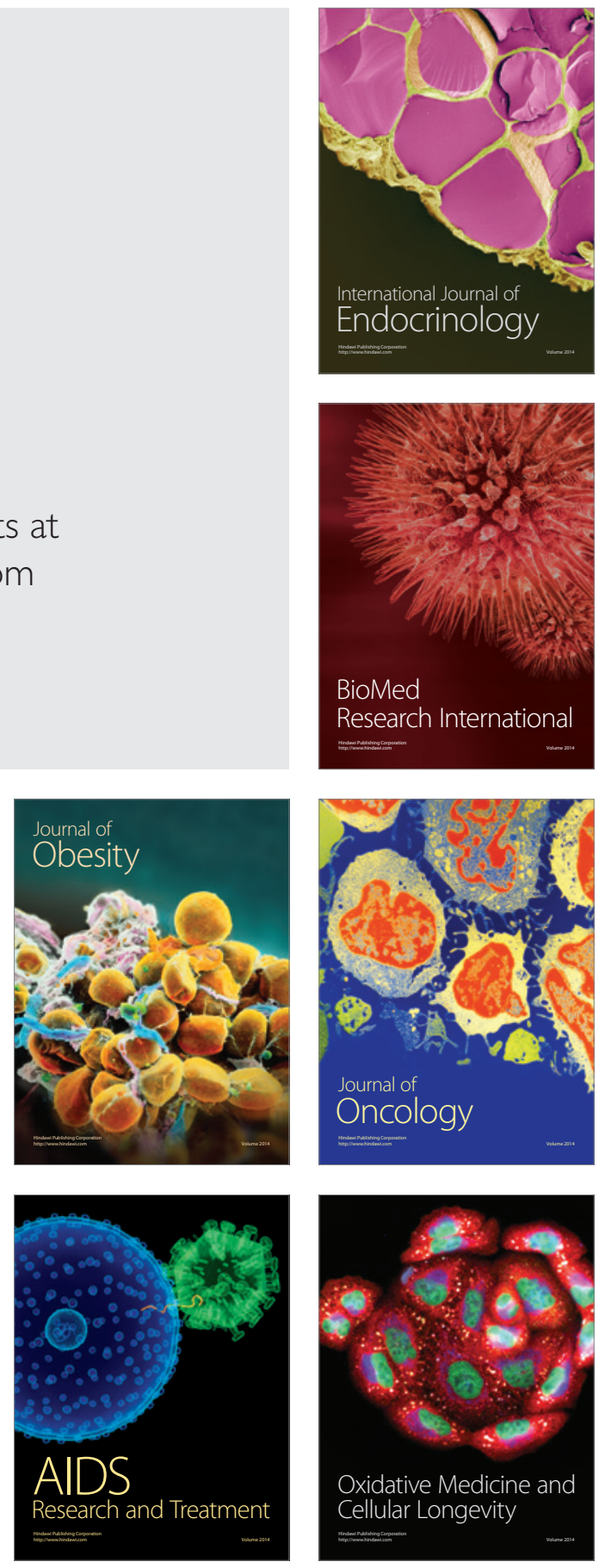